\title{
Presencia de hongos y contaminación con micotoxinas en ensilajes para alimentación de rumiantes. Artículo de Revisión
}

\section{Presence of molds and contamination with mycotoxins in silages for ruminant feeding: Review}

\author{
Carlos Alpízar Solís*
}

* Departamento de Nutrición Animal, Escuela de Medicina Veterinaria, Universidad Nacional, Costa Rica. Correo electrónico: carlos.alpizar.solis@una.cr

Recibido: 26 de Noviembre de 2014. Corregido: 03 de Octubre de 2015. Aceptado: 01 de Noviembre de 2015.

Resumen: Diversos estudios han identificado el crecimiento de hongos en forrajes ensilados para alimentar rumiantes domésticos, capaces de producir toxinas de importancia para la salud pública y animal.

El objetivo de esta revisión es recopilar los resultados de diversas investigaciones que identificaron hongos y micotoxinas con riesgo conocido en ensilajes de diversos materiales en varias regiones del mundo utilizados para alimentar rumiantes. En segundo lugar, describir las especies de hongos más comúnmente identificadas por diversos autores en alimentos ensilados para rumiantes, y los factores que favorecen su presencia y desarrollo, con la consecuente producción de micotoxinas. Por último, describir algunas medidas para prevenir la contaminación de los ensilajes con micotoxinas, y se muestra la necesidad de realizar investigaciones relacionadas con la presencia de micotoxinas en alimentos para rumiantes en Costa Rica.

Los principales efectos en rumiantes de las micotoxinas encontradas en los ensilajes se asocian a alteraciones reproductivas y del sistema inmunológico, así como del sistema digestivo. Los principales géneros identificados en los estudios revisados alrededor del mundo son Penicillium spp, Fusarium spp y Aspergillus spp. Diversos estudios reportan la contaminación de ensilajes principalmente con aflatoxinas (AFB1), fumonisinas (FB1), tricotecenos (DON, T2) y zearalenona. Factores como la presencia de oxígeno durante el ensilaje, la temperatura ambiental, el embalado y el manejo postcosecha de los forrajes tienen una importancia notable como facilitadores del desarrollo de los hongos y la consecuente producción de toxinas.

Palabras clave: hongos, ensilajes, micotoxinas, ganado, forrajes, contaminación por hongos.

Abstract: Several studies have identified mold growing in ensiled forage for domestic ruminant feeding, capable of producing important toxins for public and animal health.

The main aim of this review is to create a compilation of the results of several studies that identified molds and mycotoxins of known risk in silages made from different materials in several world regions used for ruminant feeding. Secondly, this review describes the fungus species most commonly identified by several authors, and the factors promoting their presence and development, as well as the resulting mycotoxin production. Finally, some measures to prevent mycotoxin contamination in silages are described, and the need for further research regarding the presence of mycotoxins in ruminant food in Costa Rica is shown. 
The main health effects on ruminants of mycotoxins found in silages are associated with impaired reproductive and immunologic functions, and digestive system alterations. The main genera of fungi identified in studies around the world reviewed for this paper are Penicillium spp, Fusarium spp and Aspergillus spp. Several studies reported contamination on silages, mainly with aflatoxins (AFB1), fumonisins (FB1), tricothecenes (DON, T2) and zearalenonalarenone.

Factors like oxygen present during the ensiling process, environmental temperature, packaging conditions, and post harvesting management are of remarkable importance as promoters of fungus growth and further mycotoxin production.

Key words: fungi, silage, mycotoxins, cattle, forages, fungi contamination

\section{INTRODUCCIÓN}

El ensilaje de forrajes es un método de conservación popularizado desde hace ya algunos años, sin embargo se ha utilizado siglos atrás. Mediante el ensilaje se conserva la calidad nutritiva de los forrajes y otros materiales empleados en la alimentación de rumiantes mediante fermentación láctica anaeróbica (Kung 2001), para garantizar la alimentación de los animales con ingredientes de buena calidad nutritiva en épocas de escases. Los forrajes conservados mediante ensilaje suelen constituir una parte importante de las dietas del ganado en sistemas intensivos y semi intensivos en Costa Rica, y se utilizan principalmente en el ganado lechero como una forma de garantizar el consumo de fibra y de disminuir el costo de la alimentación, con el objetivo principal de mejorar el rendimiento económico de éstos sistemas (Tobía et al. 2004). Además, la volatilidad de los precios de los insumos agropecuarios como los granos (Cámara Nacional de Productores de Leche 2013), y la variabilidad en las condiciones meteorológicas anuales debido al cambio climático (Comité Regional de Recursos Hidráulicos \& Sistema de la Integración Centroamericana 2014), con el consecuente efecto sobre la producción de forrajes, ha motivado el uso de ensilajes, especialmente en sistemas ganaderos de leche.

Sin embargo, se sabe que generalmente estos materiales contienen un importante grado de contaminación microbiológica (Johansson et al. 2005), especialmente si muestran algún grado de deterioro (Fenlon \& Wilson 1998). A esto se agrega el riesgo de la presentación de algunos desórdenes metabólicos en animales, asociados al bajo pH del ensilaje (Wilkinson 1999). Esta contaminación es riesgosa, no solo por la posible presencia de patógenos como Clostridium botulinum (Notermans et al. 1979), Listeria monocytogenes y Escherichia coli (Fenlon \& Wilson 1998), sino también por la presencia de hongos filamentosos llamados de forma general mohos, que producen metabolitos tóxicos (micotoxinas) que perjudican la producción y la salud de los animales. Estos mohos son un grupo de especies que pueden ser saprófitos, así como patógenos de plantas. Los géneros más relevantes son Fusarium, Alternaria, Cladosporium, Penicillium y Aspergillus (Auerbach 2003).

Algunas especies de hongos contaminantes son adquiridas en el material a ensilar durante la cosecha en campo, y otros son adquiridos durante el proceso de ensilado y almacenaje y la identificación de ciertas especies de hongos en los ensilajes hace posible en cierta 
medida identificar el sitio de contaminación (Baliukoniene et al. 2012). Sin embargo, la reducción rápida del pH en los ensilajes gracias a bacterias como Lactobacillus, es capaz de inhibir el crecimiento de hongos (Dogi et al. 2013). Por tanto, el proceso de ensilaje puede tanto favorecer como inhibir la presencia de estos microorganismos en función del manejo mismo del proceso para el ensilaje, aunque de forma difícil de prever.

Las micotoxinas son metabolitos secundarios producidos por ciertas especies de hongos cuando se exponen a ciertas condiciones ambientales (Peña et al. 2010; Skladanka et al. 2013). Dentro de las micotoxinas más importantes están las aflatoxinas (especialmente la B1), los tricotecenos, la ocratoxina A, la zearalenona y las fumonisinas (Duarte \& Villamil 2006). Algunas de las más comunes en los forrajes son el deoxinivalenol (DON) (Baliukoniene 2012), y la zearalenona (ZEARALENONA), frecuente en los alimentos ensilados (Fink \& Gremmels 2008). Además, la fumonisina y la aflatoxina también son contaminantes de importancia (Miller 2008).

Es posible que algunas micotoxinas estén conjugadas con azúcares (glucosilación) de cereales como el maíz, como un mecanismo de detoxificación de las plantas, pero que son liberadas mediante hidrólisis en el tracto digestivo de los animales,y de esta forma recuperan su forma activa (Rasmussen et al. 2012, Berthiller et al. 2013).

De todas las micotoxinas, se han estudiado muy pocas, aunque existe una gran cantidad (Streit et al. 2013). Los efectos de estas moléculas son varios, e incluyen los teratogénicos, citotóxicos, apoptóticos, genotóxicos, carcinogénicos, inmunodepresores, hepatotóxicos, entre otros (Duarte \& Villamil 2006).

Es además importante tener en cuenta que la presencia de micotoxinas en alimentos es un riesgo para la salud pública, pues es posible la contaminación de productos de origen animal con éstas, debido a la ingestión por los semovientes (Driehuis \& Oude 2000). El consumo de micotoxinas en los seres humanos es facilitado tanto por el consumo de productos de origen vegetal como de origen animal, que son contaminados cuando los animales consumen cantidades importantes de micotoxinas que son transportadas a los productos finales como la carne, leche o huevos (Duarte \& Villamil 2006, Battacone et al. 2010, Bandera et al. 2011, Baliukoniene et al. 2012).

Además de los efectos de las micotoxinas sobre la salud del ganado, los efectos sobre la salud de los seres humanos, quienes son en la mayoría de los casos el último de los niveles de la cadena alimenticia, están ampliamente documentados en numerosos estudios.

El objetivo de esta revisión es hacer una recopilación de los resultados de diversas investigaciones que identificaron hongos y micotoxinas en ensilajes para alimentar rumiantes, con riesgo conocido para la salud humana y animal. En segundo lugar, describir las especies de hongos más comúnmente identificadas por diversos autores en alimentos ensilados para rumiantes, y los factores que favorecen su presencia y desarrollo, con la consecuente producción de micotoxinas. Por último, se busca discutir de forma general sobre las medidas para la prevenir la contaminación de los ensilajes con micotoxinas, y 
se muestra la necesidad de realizar investigaciones relacionadas con la presencia de micotoxinas en alimentos para rumiantes en Costa Rica.

\section{Efectos en el ganado del consumo de micotoxinas}

En el caso de los rumiantes, la especie es un factor muy importante en los efectos de las micotoxinas sobre su organismo y en la presentación de cuadros clínicos asociados a éstas, pues el rumen es el órgano responsable de una buena parte de la transformación, activación e inactivación de micotoxinas, que ocurre gracias a la acción de los microorganismos ahí presentes, especialmente bacterias (Upadhaya et al. 2010). Pero algunas moléculas pueden salir del rumen sin sufrir ninguna modificación o convertidas en otros metabolitos que pueden conservar su actividad biológica (Dogi et al. 2011).

Debido a la importancia de estos hechos en relación con la salud animal y la salud pública, a continuación se explica la toxicocinética de las principales micotoxinas halladas en ensilajes.

\section{Toxicocinética}

\section{Aflatoxinas}

Como muchas otras micotoxinas, las aflatoxinas absorben en el tracto gastrointestinal rápidamente por difusión pasiva a nivel ruminal principalmente (Cook et al. 1986). El órgano en el que se metabolizan las aflatoxinas es principalmente el hígado, gracias a la actividad del citocromo p450, que es capaz de transformar la AB1 en AB1 8,9 epóxido, AM1, AB1 dihidrodiol y conjugados con la molécula de glutatión (Kuilman et al. 1998, 2000), aunque es posible que los microorganismos ruminales sean capaces de convertir AB1 en AM1 (Nielson 2012). Es por cierto, en el metabolismo de la aflatoxina B1 que se han centrado las investigaciones.

La principal ruta de detoxificación es la glucorono conjugación, la conjugación con sulfatos y con glutatión. Las aflatoxinas pueden ser excretadas en leche, orina, semen y bilis, y también pueden encontrarse en la carne y en las vísceras como el hígado y el riñón de animales faenados (Coppock et al. 2012). La etapa de la lactancia en vacas tiene un efecto sobre la excreción de AM1 en leche, pues las vacas en lactancia temprana excretan hasta tres veces más micotoxina AM1 en la leche que las vacas en lactancia tardía (Frobish et al. 1986). Baliukoniene et al. (2012) encontraron valores medios de aflatoxina M1 en leche de hasta $0,01 \mu \mathrm{g} / \mathrm{l}$. Debido a que las micotoxinas se asocian a la proteína de la leche, adquieren estabilidad en la leche y pueden ser encontradas incluso en derivados lácteos en concentraciones mayores que en la leche (Coppock et al. 2012).

\section{Fumonisina}

En el caso de la fumonisina, aunque su toxicocinética y toxicodinamia ha sido principalmente estudiada en cerdos, se sabe que se absorbe en el tracto gastrointestinal de mamíferos por 
difusión pasiva debido a su comportamiento polar. En general, la fumonisina sufre escaso metabolismo a nivel ruminal. Luego de conjugarse a nivel hepático durante la fase II del metabolismo hepático, es excretada en orina y en heces.

A diferencia de las aflatoxinas, la fumonisina prácticamente no se secreta en la leche o es detectable en la carne, por lo que en este sentido el riesgo de su consumo en productos de origen animal es bajo (Smith 2012).

\section{Ocratoxina}

La ocratoxina se absorbe fácil y rápidamente en el estómago e intestino delgado de especies monogástricas, sin embargo, en rumiantes sufre hidrólisis a nivel ruminal por las enzimas de bacterias y protozoarios, por lo que la cantidad detectada en carne o leche suele ser muy poca (Hult et al. 1976), sin embargo, Blank \& Wolffram (2009) sugieren que efectivamente es posible la secreción de ocratoxina $A$ en la leche.

La ocratoxina que escapa al metabolismo ruminal, se metaboliza en el tejido gastrointestinal, riñón e hígado, y da origen a la ocratoxina alfa, a través de quimotripsina y carboxipeptidasa A (Suzuki et al. 1977). Las características de la flora del tubo digestivo de los rumiantes hacen posible disminuir sustancialmente la absorción de la Ocratoxina A (Jouany \& Diaz 2005), sin embargo, es recomendable evitar el consumo prolongado debido a la acumulación de la sustancia en los tejidos. Por este motivo, la aparición clínica de toxicosis en esta especie es poco frecuente (Battacone et al. 2010). La excreción se da generalmente por orina y heces (Höhler et al. 1999), y la excreción por orina de ocratoxina alfa se socia principalmente a la recirculación entero hepática. Debido al metabolismo de la ocratoxina en el rumen, su excreción en leche es muy poca, al igual que el paso a través de la barrera placentaria.

\section{Tricotecenos}

Al igual que con la ocratoxina, los tricotecenos se absorben rápidamente en estómago e intestino delgado de mamíferos monogástricos, sin embargo, en rumen son metabolizados ampliamente. Por ejemplo, DON es transformada rápidamente en rumen a DOM-1, que es un metabolito desactivado, y que puede ser absorbido y luego conjugado (glucorono conjugación) para ser eliminado. Por este motivo, muy poca DON es absorbida a nivel gastrointestinal (Mostrom \& Raisbeck 2012), y la excreción en orina es principalmente de los conjugados de DON y DOM-1. Además, se ha comprobado que el nivalenol y el fusarenon $X$ (luego de ser biotransformado a nivalenol) pueden pasar a través de la placenta y la leche de ratones hasta los tejidos de los fetos, en donde alcanzan concentraciones similares a los tejidos de la madre (Poapolathep et al. 2004b).

\section{Zearalenona}

La zearalenona se absorbe fácil y rápidamente tras la ingesta oral, luego de que sufre una serie de modificaciones a nivel ruminal, que dan origen a alfa zearalenol, y en menor 
medida, beta zearalenol (Kiessling et al. 1948). La conjugación de éstos metabolitos se lleva a cabo principalmente a nivel hepático gracias a la hidroxiesteroide deshidrogenasa. La zearalenona y sus metabolitos sufren recirculación enterohepática, y la principal vía de excresión es biliar. Sin embargo, se ha observado que la tasa de pasaje ruminal puede modificar la absorción de la zearalenona y sus metabolitos (Seeling et al. 2005), pues a mayor tasa de pasaje se da menor absorción de las toxinas. Un estudio demostró que los búfalos de agua son capaces de realizar una bioactivación de la zearalenona a nivel hepático y que además es perpetuada por la circulación entero hepática (Hassan et al. 2010).

Aunque la zearalenona, alfa zearalenona y beta zearalenona pueden secretarse en la leche de vacas y ovejas que consuman altas dosis (Hagler et al. 1980; Mirocha et al. 1981), esta es muy poca y suele ocurrir durante un corto periodo de tiempo (Mostrom 2012).

\section{Efectos biológicos}

\section{Efectos en la alimentación}

En el ganado, la presencia de hongos y de micotoxinas en ensilajes se ha asociado con una disminución del consumo de alimentos, que produce una disminución de la absorción de nutrientes, lo que a su vez reduce la función metabólica, altera la función endocrina y reduce la función inmunológica (Alonso et al. 2013). En consecuencia, la disminución del consumo de forrajes contaminados con hongos y micotoxinas (y consecuentemente disminución del consumo de fibra) pueden desencadenar una disbacteriosis y acidosis láctica ruminales, que conducen a un aumento de la conversión alimenticia, pérdida de peso, diarrea moderada (con presencia de fibras no digeridas en las heces -Baliukoniene et al. 2012), además de disminución de la función reproductiva asociada, por ejemplo, a una disminución del consumo de energía. No obstante, estos síntomas pueden variar en función de la cantidad y tipo de micotoxinas consumidas, así como del tiempo de exposición a las mismas y la sensibilidad de los animales. El ganado lechero es más susceptible que las ovejas a las micotoxinas, y los animales jóvenes son más susceptibles que los animales adultos (Pereyra et al. 2008). Por ejemplo, en ganado en desarrollo es posible el consumo de hasta $9 \mathrm{mg} / \mathrm{kg}$ de alimento de DON y de hasta $12 \mathrm{mg} /$ kg de alimento en animales en finalización.

Por otro lado, en terneras lecheras el consumo de entre 0.32 y $0.64 \mathrm{mg} / \mathrm{kg}$ de alimento de toxina T-2 es capaz de producir abomasitis, úlceras abomasales y enteritis moderada (Mostrom \& Raisbeck 2012).

También, la zearalenona puede modificar la microflora del rumen, pues posee efectos antimicrobianos y antiprotozoáricos (Nesic et al. 2010).

Por tanto, los efectos de las micotoxinas en la alimentación y en la función digestiva son diversos, por lo que el control del contenido de micotoxinas en los alimentos para rumiantes debe vigilarse, aún y cuando estos pueden modificar considerablemente estas moléculas a nivel ruminal. 


\section{Efectos en la reproducción}

Las micotoxinas pueden afectar de forma indirecta la reproducción en bovinos, por ejemplo, debido a una disminución del consumo de alimento y de energía a causa de la contaminación con micotoxinas. Sin embargo, se han estudiado en mayor medida los efectos directos de la zearalenona sobre la función reproductiva, motivado principalmente por sus efectos hiperestrogénicos. La zearalenona y sus metabolitos interactúan con un receptor intracitoplásmico para el $17 \beta$ estradiol, que posteriormente induce a nivel nuclear la síntesis de RNA y de proteínas que dan origen al hiperestrogenismo (Katzenellenbogen 1979). Además, se ha demostrado un efecto inhibitorio de la zearalenona sobre la proliferación de linfocitos T y B in vitro (Forsell \& Petska 1985).

En un estudio hecho por Weaver et al. (1986) se describieron muy pocos efectos del consumo de zearalenona sobre la reproducción en bovinos, a excepción de una tendencia a la disminución del tamaño de los cuerpos lúteos y al incremento en las concentraciones de hemoglobina en vacas no lactantes ni gestantes. Sin embargo, otros autores han reportado crecimiento de glándulas mamarias en novillas (Bloomquist 1982, Coppock et al. 1990), comportamiento de estro e infertilidad tanto en novillas como en vacas (Roine et al. 1971, Coppock et al. 1990), así como disminución de la producción de leche, del consumo de alimento e inflamación de la vulva (Ványi et al. 1974).

No obstante, muchos de los efectos clínicos sobre la reproducción y la fisiología reproductiva de la zearalenona se han observado y estudiado en cerdos, debido a su sensibilidad a la toxina, asociado a una baja capacidad de glucoronidación de esta especie (Fink-Gremmels \& Malekinejad 2007).

\section{Efectos sobre la actividad inmunológica}

Otro de los efectos importantes que ejercen las micotoxinas es el inmunosupresor, como en el caso del ácido micofenólico, producido por varias especies de hongos (Puel et al. 2005). En ratones se ha identificado un efecto apoptótico del nivalenol sobre los linfocitos CD4(+) y CD8(+) del timo, tanto in vitro (Poapolathep et al. 2004a) como in vivo (Poapolathep et al. 2003); sin embargo, en este último estudio se logró determinar que los primeros tejidos linfoides de ratones afectados cuando se ingiere nivalenol son las placas de Peyer y el timo, lo que a su vez induce un una estimulación de las células $B$ secretoras de inmunoglobulina $A$, aproximadamente 9 horas luego de la ingesta de la micotoxina, gracias a la producción de interleucinas por las células de los primeros tejidos afectados. No obstante, aunque estudios similares no se han realizado en rumiantes, Korosteleva et al. (2007) observaron una disminución en la concentración sérica de lgA en vacas lecheras alimentadas con dietas contaminadas de forma natural con DON principalmente, por lo que, como el mismo autor menciona, este parámetro no se comporta de forma constante en todas las especies, y por lo tanto pueden existir otros mecanismos inmunosupresores involucrados. Además, se ha visto que las alfatoxinas pueden incrementar los conteos bacterianos en la leche de las vacas, y disminuir la actividad bacteriostática y del complemento en el suero de terneros (Coppock et al. 2012). 
Otras micotoxinas tienen efectos sobre el tejido linfoide, como en el caso de la fumonisina B1, la cual ha demostrado tener un efecto moderado sobre la blastogénesis de linfocitos en terneros (Osweiler et al. 1993) que, sumado a efectos citotóxicos moderados en hepatocitos, indica un mecanismo de acción relacionado con la afectación de la integridad de las membranas celulares.

\section{Efectos sumatorio y/o sinérgico}

La presencia de varias micotoxinas en los alimentos (caso común en la práctica) puede tener un efecto sumatorio o sinérgico en el animal, como en el caso de los efectos sobre el sistema inmunológico y sobre el hígado (Coppock et al. 2012). Además, algunas enfermedades hepáticas preexistentes como la fasciolosis, pueden incrementar la susceptibilidad de los rumiantes a las micotoxinas (Osuna et al. 1977).

Los efectos negativos de la interacción de las aflatoxinas y la toxina T-2 sobre la respuesta inmune en aves ha sido estudiada por Huff et al. (1988) y por Manafi et al. (2012), que sugiere un efecto similar en otras especies de monogástricos.

Madhyastha et al. (1994) observaron que el consumo de las toxinas DON, NIV, T-2, zearalenona y fumonisina $\mathrm{B} 1$ juntas en ratones produjo una disminución de la síntesis de ADN significativamente mayor que cuando se comparó el mismo efecto con el consumo individual de cada toxina.

En cerdos, niveles de hasta $0,025 \mathrm{~g} / \mathrm{mL}$ de DON en el suero pueden incrementar la susceptibilidad a la infección con Salmonella typhimurium (Vandenbroucke et al. 2009), lo que muestra la interacción entre las micotoxinas con otros agentes patógenos, que puede considerarse como una interacción sinérgica.

Los datos anteriores dejan ver que es necesario considerar las interacciones entre toxinas, y entre éstas y agentes patógenos, en la presentación y exacerbación de los síntomas asociados con el consumo de las toxinas y de enfermedades infecciosas.

\section{Especies de hongos productores de micotoxinas identificadas en ensilajes.}

Diversos estudios han identificado las especies de hongos presentes en ensilajes elaborados en condiciones variables, y han tratado de establecer relaciones entre la naturaleza del ensilaje y la presencia de dichos microorganismos.

Baliukoniene et al. (2012) estudiaron la contaminación de ensilajes con hongos y micotoxinas en Lituania. Se muestrearon silos de trinchera y de paca, de maíz y mezclas de forrajes. Observaron que la mayor cantidad de géneros fue aislada de ensilajes de mezclas de pastos preparados en pacas. Las especies de hongos tóxicos aisladas fueron Aspergillus nigger y Fusarium poae (ensilaje de trébol); en Aspergillus parasiticus (ryegrass); Aspergillus flavus y Fusarium solani (mezcla de pastos); y Aspergillus fumigatus, Fusarium sporotrichoides, Penicillium expansum y Trichoderma harzianum en ensilaje de maíz. Lo 
anterior indica que las especies en la población de hongos de los ensilajes podrían estar influenciadas por el forraje utilizado, relacionado con la composición química del forraje e incluso con la capacidad tamponante de ciertos forrajes como las leguminosas. Además, como lo demuestran Keller et al. (2012), la temperatura del ensilaje durante y después de la fermentación, también puede influenciar el crecimiento de ciertas cepas de hongos de $A$. fumigatus, hecho que asociaron directamente con la producción de micotoxinas. Es posible que la frecuencia de forrajes y pasturas que contienen micotoxinas y hongos productores de micotoxinas sea mayor de lo que se cree. Por ejemplo, Engels \& Krämer (1996) hallaron micotoxinas producidas por hongos del género Fusarium en el $67 \%$ de los pastos que estudiaron, en concentraciones de hasta $4,75 \mathrm{ppm}$. No obstante, el desarrollo de hongos, cómo los del género Fusarium spp, depende de factores como la localización y el ambiente (Ovando et al. 2013), por lo que el tipo de hongos y la producción (presencia) de micotoxinas (como las producidas por Fusarium spp) no son constantes en todos los ensilajes ni en todas las regiones del planeta.

Eckard et al. (2011) encontraron una incidencia de infección con Fusarium de un $46 \%$ en plantas de maíz antes de la cosecha, y las especies más prevalentes fueron $F$. sporotrichoides, $F$. verticillioides, F. graminearum, F. avenaceum, F. proliferatum y $F$. equiseti. También determinaron que la apariencia de síntomas visuales de infección del maíz con Fusarium no es un parámetro adecuado para predecir el posible contenido de toxinas en el ensilaje de maíz. Estos datos también concuerdan con los encontrados por Van Asselt et al. (2012) en Holanda, quienes observaron que el $50 \%$ de las muestras de ensilajes de maíz que estudiaron resultaron positivas para Fusarium, donde a la vez las especies más frecuentes fueron F. crookwellense, F. graminearum, F. culmorum, F. sporotrichioides y F. equiseti.

O'Brien et al. en el 2010, dirigieron un estudio para identificar las especies de hongos presentes en la superficie de silopacas en Irlanda asociado a las características de los ensilajes y a las prácticas de las fincas en la preparación de los mismos. Observaron que el hongo predominante en silopacas fue Penicillium roqueforti, el cual estuvo presente en el $42 \%$ de las pacas evaluadas, y que además incrementa su presencia conforme aumenta el tiempo de almacenaje del ensilaje. Otros hongos encontrados fueron Schizophyllum comune, Pichia fermentans, Fusarium culmorum y Penicillium paneum. Según los autores, los factores que más influyen para la aparición de áreas afectadas con crecimiento fúngico en los ensilajes fueron el clima durante la cosecha y la región geográfica donde se elaboraron los ensilajes, pues los forrajes cosechados en clima seco presentaron menor crecimiento fúngico que los cosechados en condiciones húmedas. Además la presencia de daños en el material utilizado en la envoltura de la paca también mostró tener influencia importante sobre el crecimiento de hongos. Estos resultados refuerzan el hecho de que el clima y el proceso de ensilaje tienen un papel preponderante en el desarrollo de hongos con y sin capacidad toxigénica. Penicillium roqueforti también fue la especie aislada con mayor frecuencia en el estudio realizado con ensilajes de maíz en Dinamarca por Storm et al. (2010), junto con Zygomicetes (Mucor spp), Penicillium paneum y Aspergillus fumigatus; tanto en ensilajes con crecimiento fúngico visible como en ensilajes libres de crecimientos 
macroscópicamente visibles. Estos autores no encontraron una relación significativa entre las características químicas y microbiológicas de los ensilajes estudiados y la presencia de hongos filamentosos, por tanto no es posible asociar la presencia de hongos con la composición química o la población bacteriana en los ensilajes.

González et al. realizaron un estudio en 2008 en Argentina para determinar la presencia de hongos en ensilajes, así como la presencia de micotoxinas. Para ello estudiaron dos silos de maíz, tomaron muestras pre y post fermentación y analizaron la presencia visual de mohos, la presencia de micotoxinas y características físicas de los materiales. Encontraron que el género de hongos más frecuente en los silos estudiados fue Aspergillus (78\%), hongos levaduriformes (65\%) y Fusarium con $62 \%$. A su vez, las especies más frecuentes de Aspergillus fueron A. flavus (53\%), A. fumigatus (30\%) seguido por A. nigger, y de las 8 especies de Fusarium encontradas, F. verticillioides fue la más frecuente (77\%). Otro estudio realizado en ese mismo país (Roigé et al., 2009), señala que en alimentos fermentados (maíz y trigo), Penicillium spp (74\%), Aspergillus spp (32\%) y Scopulariopsis spp (21\%) fueron las especies las especies con mayor presencia, y para conocimiento del autor, es el único estudio que ha reportado Scopulariopsis spp en alimentos para consumo animal sometidos a conservación por procesos fermentativos. Sin embargo, estos hallazgos muy similares a los reportados por Reyes et al. (2008) en México (excepto por la observación de Mucor spp en lugar de Scopulariopsis spp). Los datos anteriores dejan ver también que existe gran diferencia en las especies de hongos halladas en los ensilajes en diferentes regiones geográficas, sin embargo es claro que los géneros más frecuentemente hallados en estos materiales son Fusarium, Penicillium y Aspergillus. Por tanto, existe la necesidad de identificar las especies de importancia y las micotoxinas en regiones tropicales que están más frecuentemente presentes en los ensilajes.

Tanto el contenido de materia seca como el pH de los ensilajes también parecen tener un efecto importante sobre el desarrollo de cier tos hongos, y posiblemente, sobre la producción de micotoxinas (O'Brien et al. 2010). Es necesario recalcar que la presencia de múltiples especies de hongos en los ensilajes es un hecho común, y una importante cantidad de las especies presentes pueden ser productoras de micotoxinas (Mansfield \& Kuldau 2007).

El cuadro 1 muestra las principales especies de hongos productoras de micotoxinas más frecuentemente aisladas que reportan autores de diversas regiones del mundo en varios ingredientes usados para alimentación de ganado. 
Cuadro 1. Géneros y especies de hongos filamentosos y levaduras más frecuentes en ensilajes y otros materiales fermentados, reportados por autores de diversas regiones del mundo.

\begin{tabular}{|c|c|c|c|}
\hline Autor & Géneros y especies reportados & País & Material estudiado \\
\hline \multirow{3}{*}{$\begin{array}{l}\text { Baliukoniene et al. } \\
2012\end{array}$} & Aspergillus (0.9-15,7\%) & Lituania & \multirow{3}{*}{$\begin{array}{l}\text { Ensilaje de maíz, trébol, ryegrass y } \\
\text { mezcla de pastos }\end{array}$} \\
\hline & Penicillium (1.2-12.6\%) & & \\
\hline & Rhizopus (0.6-14.3\%) & & \\
\hline \multirow{4}{*}{ Keller et al. 2012} & Aspergillus spp $26.16 \%$ (18-37) & \multirow{4}{*}{ Brasil } & \multirow{2}{*}{$\begin{array}{l}\text { Maíz, sorgo, granos cervecería pre } \\
\text { fermentación }\end{array}$} \\
\hline & -A. fumigatus $25.7 \%(25-26)^{\square}$ & & \\
\hline & Aspergillus spp 42.16\% (22.5-54) & & \multirow{2}{*}{$\begin{array}{l}\text { Maíz, sorgo, granos cervecería } \\
\text { post fermentación }\end{array}$} \\
\hline & -A. fumigatus $32.3 \%(22-43)^{\square}$ & & \\
\hline \multirow{6}{*}{ Eckard et al. 2011} & Fusarium sporotrichioides $16.3 \%$ & Suiza & \multirow{6}{*}{ Ensilaje de maíz } \\
\hline & Fusarium verticillioides $16.1 \%$ & & \\
\hline & Fusarium graminearum $15.6 \%$ & & \\
\hline & Fusarium avenaceum $11.4 \%$ & & \\
\hline & Fusarium proliferatum $10.9 \%$ & & \\
\hline & Fusarium equiseti $8.6 \%$ & & \\
\hline \multirow{5}{*}{ Van Asselt et al. 2012} & Fusarium crookwellense $19 \%$ & Holanda & \multirow{5}{*}{ Ensilaje de maíz } \\
\hline & Fusarium graminearum $14 \%$ & & \\
\hline & Fusarium culmorum $12 \%$ & & \\
\hline & Fusarium equiseti $10 \%$ & & \\
\hline & Fusarium sporotrichioides $10 \%$ & & \\
\hline \multirow{5}{*}{ O'Brien et al. 2010} & Penicillium roqueforti $42 \%$ & Irlanda & \multirow{5}{*}{ Ensilaje de pastos } \\
\hline & Schizophyllum comune $21 \%$ & & \\
\hline & Penicillium paneum $5 \%$ & & \\
\hline & Pichia fermentans $10 \%$ & & \\
\hline & Geotrichum 4\% & & \\
\hline \multirow{4}{*}{ Storm et al. 2010* } & Penicillium roqueforti $83.4 \%$ (67-100) & Dinamarca & \multirow{4}{*}{ Ensilaje de maíz } \\
\hline & Zygomycetes 62\% (35-80) & & \\
\hline & Penicillium paneum $47.6 \%$ (28-65) & & \\
\hline & Aspergillus fumigatus $28.2 \%$ (11-60) & & \\
\hline \multirow{3}{*}{ Roigé et al. 2009} & Penicillium spp $74 \%$ & Argentina & \multirow{3}{*}{ Maíz y trigo fermentados } \\
\hline & Aspergillus spp $32 \%$ & & \\
\hline & Scopulariopsis spp $21 \%$ & & \\
\hline \multirow{8}{*}{ González et al. 2008} & Aspergillus spp 78\%: & Argentina & \multirow{8}{*}{ Ensilaje de maíz } \\
\hline & $-A$. flavus $53 \%{ }^{\square}$ & & \\
\hline & -A. fumigatus $30 \%$ & & \\
\hline & -A. nigger $10 \%$ & & \\
\hline & Fusarium spp $62 \%$ : & & \\
\hline & - F. verticillioides $77 \%^{\dagger}$ & & \\
\hline & - F. solani $5 \%^{\dagger}$ & & \\
\hline & -F. equiseti $5 \%^{\dagger}$ & & \\
\hline
\end{tabular}

* Se muestran los promedios de los porcentajes de muestras positivas para cada especie, obtenidas 3, 5, 7, 9 y 11 meses post ensilaje. Los rangos se muestran entre paréntesis.

$\square$ Densidades relativas de especies del género Aspergillus.

† Densidades relativas de especies del género Fusarium 


\section{Factores que favorecen la producción y presencia de micotoxinas en ensilajes.}

Según Miller (2008), se pueden identificar cuatro categorías de hongos productores de micotoxinas: 1) patógenos de plantas (por ejemplo Fusarium graminearum), 2) hongos micotoxigénicos en plantas senescentes o estresadas (Fusarium verticillioides), 3) hongos que colonizan las plantas y provocan la contaminación de micotoxinas luego de la cosecha (Aspergillus flavus), 4) hongos hongos presentes en el suelo o material en descomposición que contaminan alimentos y luego proliferan durante el almacenamiento (Penicillium verrucosum). Es por ello que la contaminación con micotoxinas puede darse previo a la cosecha de los forrajes, durante la cosecha, o durante el almacenamiento (inclusive durante la fermentación) de los alimentos a ensilar, de manera que diferentes especies de hongos pueden contaminar los ensilajes en diferentes momentos, de acuerdo a las condiciones específicas de cada proceso.

Existen factores endógenos de los ensilajes que favorecen el crecimiento de mohos, como el $\mathrm{pH}$ (de mayor importancia) y la composición nutricional, así como la actividad de agua (Aw); pero también existen factores exógenos, como presencia de oxígeno, tiempo y temperatura de almacenamiento, entre otros (Auerbach 2003).

Puel et al. (2005) han sugerido que la presencia y la cantidad de hongos en un sustrato puede relacionarse directamente con la presencia y cantidad de micotoxinas en el mismo, sin embargo la presencia de hongos no siempre implica la presencia de micotoxinas, ni viceversa, debido principalmente a que la mayoría de micotoxinas son producidas, al parecer, en condiciones específicas de temperatura y humedad (por ejemplo temperaturas mayores a $85^{\circ} \mathrm{F}$ ); y a que no todos los hongos son capaces de producir las toxinas (Gotlieb 2004).

En alimentos ensilados para consumo de rumiantes se han identificado algunos factores de importancia para el desarrollo de hongos y la producción de micotoxinas. A continuación se discuten algunos de los factores que más se han estudiado por diversos autores en diferentes regiones del mundo, y que aportan una visión general de las condiciones claves a tomar en cuenta a la hora de evaluar el riesgo del desarrollo y presencia de micotoxinas.

\section{Tipo de material}

De acuerdo a diversos estudios, es común la aparición de varias micotoxinas en un mismo sustrato (cuadro 2). No obstante, es posible que el sustrato o el alimento determinen en gran medida la presencia y el tipo de hongos y micotoxinas que pueden contaminarlo, según las observaciones. Por ejemplo, en el estudio de Baliukoniene et al. en el 2012, la mayor concentración de aflatoxinas se observó en ensilaje de ryegrass en pacas (40 ppm), en el cual también resultó la mayor cantidad de micotoxinas a nivel general. También se halló zearalenona en ensilaje de mezcla de pastos preparado en trincheras (800 ppm) así como deoxinivalenol a niveles de hasta 1020 ppm en ensilaje de trébol en pacas.

Rashedi et al. (2012) midieron el contenido de zearalenona en cuatro materiales (cebada, maíz, ensilaje y grano de trigo) mediante ensayos ELISA directos. Hallaron zearalenona 
en el $14.8 \%$ de las muestras con una concentración media de $142 \mathrm{ng} / \mathrm{g}$, con contenidos significativamente mayores en el maíz, cebada y ensilaje que en el trigo $(p<0,05)$, y en mayor cantidad durante la primavera. Sin embargo la disparidad en el número de muestras de cada ingrediente es un hecho cuestionable en este estudio, desde el punto de vista de la representatividad de las muestras.

Se ha visto que algunas especies de pastos $\mathrm{C} 3$ de zona templada presentan una importante resistencia al desarrollo de hongos y a la presencia de micotoxinas (Skládanka et al. 2011). Esto sugiere que la especie de forraje utilizada para el ensilaje podría, en alguna medida, modificar positiva o negativamente del desarrollo de hongos y sus toxinas.

Finalmente, como se puede observar en el cuadro 2, varios estudios han encontrado diferentes micotoxinas en ensilaje de maíz y en diferentes concentraciones, sin embargo, es posible que este hecho se deba principalmente a que este es un forraje muy utilizado para ensilajes (las investigaciones se han centrado en este material), y no necesariamente a una susceptibilidad del forraje a los hongos y sus micotoxinas.

\section{Sellado del silo y condiciones de almacenamiento}

Las prácticas de manejo y producción de forrajes conservados (en este caso como ensilaje) en las fincas pueden favorecer en gran medida el desarrollo subsecuente de hongos $\left(O^{\prime}\right.$ Brien et al. 2010), y por tanto, la posible contaminación con micotoxinas. Se sabe que la producción de fumonisinas se ve inhibida por condiciones anaeróbicas como las de la fermentación láctica de los ensilajes (Uegaki et al. 2013, a). Sin embargo, Müller \& Amend (1997) observaron la producción de ácido micofenólico, patulina, ácido penicílico y toxina PR en condiciones aeróbicas por cepas de Penicillium roqueforti en ensilaje de maíz. Por lo tanto, el sellado inadecuado de los ensilados puede dar lugar al desarrollo de mohos debido a la presencia de oxígeno, lo que favorece su crecimiento y la producción de micotoxinas. Además, el mismo proceso de ensilaje puede favorecer la producción de micotoxinas debido al calor producido por la fermentación del forraje (Skladanka et al. 2013).

Por otro lado, se sabe que hongos como Fusarium spp. pueden ver disminuidas sus poblaciones por el proceso de ensilaje debido a la acidez y a la anaerobiosis, no obstante las toxinas producidas son muy estables y no suelen ser afectadas por estas condiciones (Eckard et al. 2011). Esto sugiere que aún en ensilajes preparados correctamente, existe una probabilidad de contaminación con micotoxinas.

\section{Condiciones ambientales durante ensilaje}

Los hongos toxigénicos pueden requerir una humedad relativa superior al $70 \%$ y producir toxinas con temperaturas entre los $5^{\circ} \mathrm{C}$ y $\operatorname{los} 25^{\circ}$ (Araya 2011). Las condiciones ambientales que favorecen la presencia y crecimiento de hongos pueden o no favorecer la producción de micotoxinas (Peña et al. 2010; Skládanka et al. 2013). Este hecho es especialmente destacable en países de regiones tropicales como Costa Rica, en donde alta humedad relativa 
y temperatura son frecuentes en la mayoría del territorio. Mansfield et al. (2007), afirman que las condiciones ambientales húmedas pueden favorecer la producción de micotoxinas producidas por hongos del género Alternaria spp, y las condiciones ambientales calurosas pero secas pueden favorecer la producción de fumonisinas en maíz, posiblemente debido a la menor resistencia a ataques por plagas en las plantas debido al estrés hídrico. Sin embargo, los autores sugieren que el uso de líneas con alta resistencia a insectos y otras plagas, así como evitar la cosecha del maíz en etapas finales de desarrollo, puede disminuir el efecto de condiciones ambientales favorables para el desarrollo de fumonisinas y otras micotoxinas similares. Es también sensato tener en cuenta que, muy posiblemente, el cambio climático actual puede favorecer la contaminación con micotoxinas en cereales (Wu et al. 2011; Van Asselt et al. 2012), en países productores y exportadores, en los que hasta hace algunos años eso no sucedía (Miller 2008).

\section{Proceso de fermentación anaeróbica}

Varios estudios han intentado esclarecer el efecto de la fermentación anaeróbica de alimentos sobre la presencia o contaminación con micotoxinas, sin embargo, no ha sido posible identificar un efecto fijo, y se puede apreciar una variación importante en los resultados obtenidos por los diferentes investigadores.

González et al. (2008) evaluaron el contenido de micotoxinas en silo de maíz pre y postfermentación, yno detectaron contaminación con aflatoxina B1 en ensilaje pre fermentación, no así en 6 muestras postfermentación. Sin embargo, sus contenidos de zearalenona no mostraron diferencia significativa entre las muestras prefermentación y postfermentación, y hallaron, en el $83.5 \%$ de las muestras, zearalenona, DON y fumonisina B1.

Por otro lado, Peña et al. (2010) estudiaron la producción de gliotoxina por Aspergillus fumigatus (A. fumigatus) aislado de alimentos destinados a la alimentación de varias especies. Estos autores no encontraron un valor detectable de gliotoxina en ensilaje de maíz, probablemente debido a las condiciones ácidas de ensilajes bien preparados. No obstante, el $28 \%$ de las cepas aisladas de $A$. fumigatus en ensilaje mostraron capacidad de producir la gliotoxina. Estos datos contrastan de forma parcial con los encontrados por Keller et al. (2012), quienes observaron hasta $70 \%$ de muestras estudiadas de maíz ensilado positivas a gliotoxina (producida por Aspergillus spp), con contenidos de 0,1 a $34 \mathrm{mg} / \mathrm{l}$, mientras que en sorgo y en granos de cervecería pre fermentación encontraron hasta $30 \%$ de muestras contaminadas, con niveles de entre 0,1 a $2 \mathrm{mg} / \mathrm{l}$ y 0,1 a $10 \mathrm{mg} / \mathrm{l}$, respectivamente. Dichos resultados sugieren que las condiciones de los alimentos durante y luego de la fermentación (como bajo pH, alta temperatura y baja tensión de oxígeno), pueden favorecer la producción de gliotoxina, contrario a lo que sucede con otras especies y sus toxinas.

Es posible apreciar un efecto muy variable del proceso de fermentación anaeróbica sobre el desarrollo y la presencia de micotoxinas, a consecuencia especialmente de la dificultad de los estudios de replicar experimentalmente de forma precisa las condiciones de $\mathrm{pH}$, temperatura, humedad y concentración de oxígeno (entre otros) en los ensilajes estudiados, 
por lo que un proceso de fermentación y ensilaje aceptables no son garantía de inexistencia de micotoxinas, mas son necesarios para disminuir el riesgo.

\section{Manejo de los cultivos}

Del manejo de los cultivos utilizados para ensilaje, el momento de cosecha (condición climática y madurez del forraje), el tratamiento de los cultivos contra los hongos y el control de hongos en la semilla pueden ser los factores que más influyen en el riesgo de producción y contenido de DON en ensilajes y plantas de maíz (Eckard et al. 2011).

Hay autores que sugieren que casi todas las micotoxinas presentes en ensilajes son producidas previo a la cosecha del forraje (Uegaki et al. 2013, b), lo cual indica que el manejo pre cosecha de los forrajes puede ser un factor importante a tomar en cuenta, si se quiere reducir el riesgo de presencia de micotoxinas. No obstante, algunos factores que afectan a los cultivos como el clima son difíciles de manejar y es necesario el desarrollo de tecnologías y prácticas de cultivo que disminuyan el riesgo de micotoxinas. Sin embargo, el manejo post cosecha y la elaboración de los ensilajes sí pueden controlarse, y gran parte de los esfuerzos por disminuir la problemática pueden basarse precisamente en ese manejo (Gotlieb 2004).

A continuación, el cuadro 2 resume las micotoxinas halladas en diferentes materiales ensilados, así como la concentración, reportados por diferentes autores. 
Cuadro 2. Micotoxinas identificadas y concentración en diferentes materiales ensilados destinados al consumo animal.

\begin{tabular}{|c|c|c|c|}
\hline Micotoxina & Autor & Material & Concentración \\
\hline Aflatoxinas & Baliukoniene et al., 2012 & $\begin{array}{l}\text { Ensilaje de pasto mixto, rye- } \\
\text { grass, trébol y maíz }\end{array}$ & $14.24 \mu \mathrm{g} / \mathrm{kg} *(7.7-21.2)$ \\
\hline \multirow{5}{*}{ Zearalenona } & Baliukoniene et al., 2012 & $\begin{array}{l}\text { Ensilaje de pasto mixto, rye- } \\
\text { grass, trébol y maíz }\end{array}$ & $357.8 \mu \mathrm{g} / \mathrm{kg} *(22.5-625)$ \\
\hline & Rashedi et al., 2012 & Ensilaje de maíz & 140 ng/gr RNR \\
\hline & González et al., 2008 & Ensilaje de maíz & $\begin{array}{l}\text { - Prefermentación: } 18 \text { ng/gr (10-25) } \\
\text { - Postfermentación: } 50 \text { ng/gr (nd-350) }\end{array}$ \\
\hline & Eckard et al., 2011 & Ensilaje de maíz & $180.9 \mu \mathrm{g} / \mathrm{kg}$ RNR \\
\hline & Driehuis et al., 2008 & Ensilaje de maíz & $174 \mu \mathrm{g} / \mathrm{kg}$ RNR \\
\hline \multirow{4}{*}{$\begin{array}{l}\text { Deoxinivalenol } \\
\text { (DON) }\end{array}$} & Baliukoniene et al., 2012 & $\begin{array}{l}\text { Ensilaje de pasto mixto, rye- } \\
\text { grass, trébol y maíz }\end{array}$ & $418.16 \mu \mathrm{g} / \mathrm{kg} *(328-471)$ \\
\hline & González et al., 2008 & Ensilaje de maíz & $\begin{array}{l}\text { - Prefermentación: } 150 \text { ng/gr (100-230) } \\
\text { - Postfermentación: } 276 \text { ng/gr (30-870) }\end{array}$ \\
\hline & Eckard et al., 2011 & Ensilaje de maíz & $1356 \mu \mathrm{g} / \mathrm{kg}$ RNR \\
\hline & Driehuis et al., 2008 & Ensilaje de maíz & $854 \mu \mathrm{g} / \mathrm{kg}$ RNR $\square$ \\
\hline Nivalenol & Eckard et al., 2011 & Ensilaje de maíz & $521.3 \mu \mathrm{g} / \mathrm{kg}$ RNR \\
\hline Ácido fusárico & Shimshoni et al., 2013 & Ensilaje de maíz & $765 \mu \mathrm{g} / \mathrm{kg}$ RNR \\
\hline \multirow{3}{*}{ Gliotoxina } & Keller at al., 2012 & Maíz & $\begin{array}{l}\text {-Prefermentación: } 0.1-2 \mathrm{mg} / \mathrm{kg} \\
\text {-Postfermentación: } 0.1-34 \mathrm{mg} / \mathrm{kg}\end{array}$ \\
\hline & & Sorgo & $\begin{array}{l}\text {-Prefermentación: } 0.1-2 \mathrm{mg} / \mathrm{kg} \\
\text {-Postfermentación: } 0.1-23 \mathrm{mg} / \mathrm{kg}\end{array}$ \\
\hline & & Granos cervecería & $\begin{array}{l}\text {-Prefermentación: 0.1-10 mg/kg } \\
\text {-Postfermentación: } 0.1-22 \mathrm{mg} / \mathrm{kg}\end{array}$ \\
\hline Fumonisina B1 & González et al., 2008 & Ensilaje de maíz & $\begin{array}{l}\text {-Prefermentación: } 600 \text { ng/gr (120-1840) } \\
\text {-Postfermentación: } 1110 \text { ng/gr (340- } \\
\text { 2490) }\end{array}$ \\
\hline $\mathrm{T}-2$ & Eckard et al., 2011 & Ensilaje de maíz & $36.14 \mu \mathrm{g} / \mathrm{kg}$ RNR \\
\hline
\end{tabular}

*Valor medio de la concentración en los diferentes materiales.

nd: no detectado; RNR: rango no reportado. ${ }^{\square}$ : promedio de las muestras recolectadas en 3 años consecutivos. 


\section{Estrategias para el control.}

El manejo de los cultivos que serán conservados a través del método de ensilado, se propone como el conjunto de estrategias o medidas más indicadas para el control de la contaminación con micotoxinas. El efecto que tienen las condiciones ambientales, el manejo de los cultivos y las características propias de cada alimento son determinantes a la hora de idear y aplicar estrategias para controlar la presencia de las toxinas.

El Consejo de Ciencias Agrícolas y Tecnología de los Estados Unidos en el 2013 (CAST por sus siglas en inglés) ha sugerido una serie de medidas generales para la prevención y disminución de la contaminación con micotoxinas en cultivos (por ejemplo forrajes para ensilar), que se han venido utilizando y probando, y que son aplicables a diversas condiciones y granjas. A continuación se describen de forma resumida estas medidas.

En cuanto al manejo precosecha, es necesario controlar el estrés antes de la cosecha en la medida de lo posible, por lo que es recomendable, por ejemplo, utilizar riego durante épocas de estrés hídrico. Es recomendable también eliminar completamente los residuos de cultivos anteriores del suelo, pues es posible la contaminación de nuevos cultivos con especies de Fusarium a partir de los residuos de cultivos anteriores. Algunos hongos toxigénicos crecen en las inflorescencias de las gramíneas, como es el caso de Claviceps purpurea, por lo que el uso de las pasturas durante el estado vegetativo justo antes de la floración es recomendable para evitar también la contaminación con toxinas como la ergotoxina. Sin embargo, también se sugiere la aplicación de otras medidas preventivas que involucran un uso más intensivo y un desarrollo mayor de tecnologías; en este sentido, la reproducción y la selección de plantas con una resistencia mayor a la presencia y desarrollo de hongos tanto saprófitos como patógenos, o el estudio de especies de microorganismos y otros agentes bióticos, con el objetivo de establecer estrategias de control biológicos de hongos toxigénicos, son las alternativas que mayor avance tienen actualmente. Sin embargo, estas medidas aún se encuentran en desarrollo, pueden tomar algunos años en ser aplicadas a campo, y debe garantizarse su factibilidad económica para los productores.

En relación al manejo post cosecha, el CAST (2013) sugiere principalmente el control de las condiciones de almacenamiento de los alimentos como la principal estrategia a aplicar para el control de las micotoxinas. En este sentido, el secado o la reducción del contenido de humedad de los forrajes antes del proceso de ensilaje, así como las condiciones de temperatura, humedad relativa y concentración de oxígeno (calidad del sellado) con las que se almacenan los ensilajes, son las prácticas que mejor previenen o reducen de micotoxinas. Es necesario tener en cuenta que las condiciones del cultivo previo a la cosecha pueden interferir con el efecto de estas medidas post cosecha, por lo que deben aplicarse conjuntamente el control previo a la cosecha y el control post cosecha.

Además, Gotlieb (2004) ha sugerido una serie de medidas generales para su aplicación antes y luego de la cosecha de forrajes para ensilaje. Este autor sugiere que antes de la cosecha se controlen las poblaciones de insectos, pues pueden servir como vectores; $y$ al igual que 
el CAST, utilizar especies de plantas que presenten una mayor resistencia al desarrollo de hongos e insectos, así como utilizar los cultivos en un estado de madurez adecuado.

En el caso del manejo post cosecha, el autor sugiere que durante el proceso de ensilado se verifique el estado de las cuchillas del equipo de picado para garantizar que el empacado del forraje se lleve a cabo de la forma adecuada, y que se realice el ensilaje en el tiempo adecuado para evitar la descomposición del material, así como verificar el sellado del silo y la reparación pronta de los eventuales daños en el material de empaque, luego del sellado. También se sugieren algunas medidas a la hora de utilizar el ensilaje como descartar las porciones que presenten daño evidente, evitar la entrada de lluvia en el silo, descartar los residuos de alimento de los comederos regularmente, diluir las micotoxinas en las dietas con alimentos limpios o con contenidos bajos de micotoxinas, así como controlar la administración de ensilaje para exponer la menor cantidad del mismo al aire y utilizar aditivos en el ensilaje o en la dieta para contrarrestar el efecto de las micotoxinas.

Precisamente, en esta última estrategia han trabajado varios investigadores. El uso de levaduras se ha planteado como una alternativa para el control de las micotoxinas en los alimentos destinados al consumo animal. Algunos autores indican que las levaduras como Saccharomyces cerevisiae pueden unir algunas micotoxinas como la ocratoxina $A$ a los glucomananos y los 1,3 beta glucanos, mecanismo que puede estar influenciado en gran medida por el pH del medio (Bank \& Wolffram 2009, Korosteleva et al. (2007) observaron que es posible disminuir los efectos de micotoxinas producidas por hongos del género Fusarium en vacas lecheras al usar glucomananos en dietas contaminadas naturalmente.

Dogi et al. (2011) encontraron que algunas cepas de Saccharomyces cerevisiae vieron reducidas significativamente los conteos de células de levaduras viables en el tracto digestivo de rumiantes, probablemente debido al efecto fungistático de la anaerobiosis, sin embargo la viabilidad de dichas células se mantuvo, y observaron que el pH no parece afectar la capacidad de las levaduras de unirse a la aflatoxina B1.

Blank \& Wolffram (2008), estudiaron el efecto de la suplementación con levaduras enteras vivas en dietas altas en concentrado para ovejas para evaluar la disponibilidad sistémica y el patrón de excreción de la ocratoxina $A(O A)$. Los autores encontraron que la absorción, distribución y eliminación de la OA y ocratoxina alfa no se vieron afectadas por la inclusión de la levadura. La inclusión de levaduras tampoco afectó la tasa de desaparición de la toxina del líquido ruminal, ni la excreción urinaria.

Nesic et al.(2010) estudiaron el efecto del uso de zeolita en dietas para terneros contaminadas con zearalenona, y aunque encontraron mayores ganancias de peso en los terneros en las dietas con zeolita ( 2 y $5 \mathrm{~g} / \mathrm{kg}$ ) en comparación con los que no, las diferencias no fueron significativas. Más aún, no hallaron diferencias entre las dietas que solo contenían zeolita o zearalenona. De Mil et al. (2015) observaron que el porcentaje promedio de zealarenona adsorbida fue entre el 0 y el 40, y que in vitro, el pH del medio y la geometría molecular de los adsorbentes juegan un papel importante en el porcentaje de adsorción de zealarenona. 
Además, se han utilizado otros aditivos como enzimas, probióticos o microorganismos productores de ácido láctico y hasta hongos que han disminuido los conteos de otros hongos y levaduras en ensilajes de alfalfa (Keller et al. 1998), pero sin una tendencia definida en el efecto.

Sin embargo, el control de los factores que mayor riesgo presentan para la contaminación de los ensilajes con micotoxinas como el manejo de los cultivos y del proceso de ensilaje y almacenaje, son las estrategias que mayor efectividad y factibilidad (inclusive económicamente) presentan en condiciones normales en las fincas. Por tanto, el uso de aditivos en el alimento para reducir la actividad y disponibilidad de las micotoxinas no se amplía en este documento, y más bien se sugiere su uso como una estrategia complementaria a las que se plantean con respecto al manejo de cultivos y ensilajes.

\section{CONCLUSIONES.}

La presencia de hongos toxigénicos y la producción de sus toxinas es un problema de salud pública importante. Las toxinas más comúnmente encontradas y frecuentemente evaluadas en ensilajes son la aflatoxina B1 y la ocratoxina $A$, junto con zearalenona y deoxinivalenol, cuyos niveles en diversos estudios han resultado muy variables en función del método de preparación de los ensilajes, el tipo de fermentación (aeróbico o anaeróbico), el material ensilado, el ambiente, entre otros.

Dos de las especies de hongos micotoxigénicos más comunes en los ensilajes son Penicillium roqueforti, Fusarium graminearum; además hongos del género Aspergillus.

El correcto manejo de los cultivos, de las etapas del proceso de ensilaje y el control de las condiciones en las que se elabora constituyen las medidas más efectivas para disminuir la contaminación de los ensilajes con micotoxinas.

Además, es necesario seguir avanzando en las investigaciones relacionadas con la presencia de micotoxinas en ensilajes para consumo de rumiantes, muy especialmente en regiones tropicales, pues las condiciones ambientales y las características de los alimentos producidos en dichas regiones favorecen, al menos teóricamente, el desarrollo de estos toxinas, lo cual representa un alto riesgo para la salud y seguridad alimentaria de las poblaciones que dependen de la producción agropecuaria de estos países.

\section{REFERENCIAS.}

Alonso V., Pereyra, C., Keller, L., Dalcero, A., Rosa, C., Chiacchiera S. \& Cavaglieri, L. 2013. Fungi and mycotoxins in silage: an overview. J Appl Microbiol. 115 (3): 367-643. doi: 10.1111/jam.12178.

Araya, 0. 2011. Problemas tóxicos de bovinos asociados con forrajes conservados y piensos [en línea]: http://www2.inia.cl/medios/biblioteca/seriesinia/NR23515.pdf. (Consulta 10 mar. 2015). 
Auerbach, H. 2003. Mould growth and mycotoxin contamination of silages: sources, types and solutions. In: Lyons T., Jacques K. (ed) Proceedings of Alltech's Nineteenth Annual Symposium. p: 247-265.

Baliukoniene, V., Bakutis, B., Vaivadaite, T., Bartkienė, E. \& Jovaišienė, J. 2012. Prevalence of fungi and mycotoxins in silage and milk in Lithuania. Vet Med Zoot. 59 (81): 9 p.

Bandera, E., Chandran, U., Buckley, B., Lin, Y., Isukapalli, S., Marshall, I., King, M. \& Zarbl, H. 2011. Urinary Mycoestrogens, Body Size and Breast Development in New Jersey Girls. Sci Total Environ. 409 (24): 5221-5227. doi: 10.1016/j.scitotenv.2011.09.029.

Battacone G., Nudda, A. \& Pulina, G. 2010. Effects of Ochratoxin A on Livestock Production. Toxins. 2 (7): 1796-1824. doi: 10.3390/toxins2071796.

Berthiller, F., Crews, C., Dall'asta, C., De Saeger, S., Haesaert, G., Karlovsky, P., Oswald, I., Seefelder, W., Speijers, G. \& Stroka, J. 2013. Masked mycotoxins: a review. Mol. Nutr. Food Res. 57 (1):165-186. doi: 10.1002/mnfr.201100764.

Blank, R. \& Wolffram, S. 2009. Effects of live yeast cell supplementation to high concentrate diets on the toxicokinetics of ochratoxin A in sheep. Food Add \& Cont. 26 (1): 119-26. doi: 10.1080/02652030802320600.

Bloomquist, C., Davidson, J. \& Pearson, E. 1982. Zearalenone toxicosis in prepubertal dairy heifers. J Am Vet Med Assoc. 189: 164-165.

Cámara Nacional de Productores de Leche. 2013. Proyecto: "Red Nacional de Pastos y Forrajes" [en línea]: http://www.proleche.com/recursos/documentos/RED_ NACIONAL_DE_PASTOS_Y_FORRAJES.pdf (Consulta: 6 mar. 2015).

Cook, W., Richard, J., Osweiler, G. \& Trampel, D. 1986. Clinical and pahtologic changes in acute bovine aflatoxicosis: rumen motility and tissue and fluid concentrations of aflatoxins B1 and M1. Am J Vet Res 47: 1187-1825.

Comité Regional de Recursos Hidráulicos (CRRH), Sistema de la Integración Centroamericana (SICA). 2014. XLIV Foro del Clima de América Central [en línea]:http://www.proleche.com/ recursos/documentos/medioAmbiente/PerspectivadelClima.pdf (Consulta: 6 mar. 2015).

Coppock, R., Mostrom, M., Sparling, C., Jacobsen, B. \& Ross, C. 1990. Apparent zearalenone intoxication in a dairy herd from feeding spoiled acid-treated corn. Vet Hum Toxicol. 32 (3): 246-248.

Coppock, R., Christian, R. \& Jacobsen, B. 2012. Aflatoxins. P 1186-1188. In: R. Gupta (ed). Veterinary Toxicology. Ed.. $2^{\text {a }}$ edición. Elsiever. Oxford, Estados Unidos.

De Mil, T., Devreese, M., De Baere, S., Van Ranst, E., Eeckhout, M., De Backer, P. \& Crobels, S. 2015. Characterization of 27 Mycotoxin Binders and the Relation with in Vitro Zearalenone Adsorption at a Single Concentration. Toxins. 7: 21-33. doi: 10.3390/toxins7010021.

Dogi, C., Armando, R., Ludueña, R., De Moreno, A., Rosa, C., Dalcero, A., \& Cavaglieri, L. 2011. Saccharomyces cerevisiae strains retain their viability and aflatoxin B1 binding ability 
under gastrointestinal conditions and improve ruminal fermentation. Food Add \& Cont. 28 (12): 1705-11. doi: 10.1080/19440049.2011.605771.

Driehuis, F. \& Oude S. 2000. The impact of the quality of silage on animal health and food safety: a review. Vet O. 22 (4): 212-216.

Duarte, S. \& Villamil, L. 2006. Micotoxinas en la Salud Pública. Rev. Salud Pública. 8 (1): 129-135.

Eckard, S., Wettstein, F., Forrer, H. \& Vogelgsang, S. 2011. Incidence of Fusarium species and mycotoxins in maize silage. Toxins. 3 (8): 949-67. doi: 10.3390/toxins3080949.

Engels, R. \& Krämer, J. 1996. Incidence of Fusaria and occurrence of selected Fusarium mycotoxins on Lolium spp. in Germany. Mycotoxin Res. 12 (1): 31-40. doi: 10.1007/ BF03192078.

Fenlon, D. \& Wilson, J. 1998. The quantitative assessment of Listeria monocytogenes growth in a laboratory ensiling system allowing limited aerobic spoilage. Grass and Forage Science. 53: 292-295. doi: 10.1046/j.1365-2494.1998.00132.x.

Fink-Gremmels, J. 2005. Mycotoxins in forages. In: Diaz D.E. (ed) The mycotoxin blue book. Nottingham University Press, Nottingham, United Kingdom. p: 249-268.

Fink-Gremmels, J. \& Malekinejad, H. 2007. Clinical effects and biochemical mechanisms associated with exposure to the mycoestrogen zearalenone. Anim Feed Sci Technol. 137 (3/4): 326-341. doi: 10.1016/j.anifeedsci.2007.06.008.

Forsell, J. \& Petska, J. 1985. Relation of 8-ketotrichothecene and Zearalenone analog structure to inhibition of mitogen-induced human lymphocyte blastogenesis. Appl Environ Microbiol. 50: 1304-1307.

Frobish, R., Bradley, B., Wagner, D., Long-Bradley, P. \& Hairston H. 1986. Aflatoxin residues in milk of dairy cattle after ingestion of naturally contaminted grain. J Food Pro. 49: 781-785.

González, M., Alonso, V., Sager, R., Morlaco, M., Magnoli, C., Astoreca, A., Rosa, C., Chiacchiera, S., Dalcero, A., \& Cavaglieri, L. 2008. Fungi and selected mycotoxins from pre- and postfermented corn silage. J. Appl. Microbiol. 104 (4): 1034-41.

Gotlieb, A. 2004. Mycotoxins in silage: A silent loss in profits [en línea]: http://www.uvm. edu/pss/vtcrops/articles/Mycotoxins.html (Consulta 9 mar. 2015).

Hassan, M., Fatemeh, R. \& Kobra, B. 2010. Zearalenone is bioactivated in the river Buffalo (Bubalus bubalis): hepatic biotransformation. Trop Anim Health Prod. 42 (6): 12291234. doi: 10.1007/s11250-010-9554-x.

Höhler, D., Südekum, K., Wolffram, S., Frohlich, A. \& Marquardt, R.. 1999. Metabolism and excretion of ochratoxin A fed to sheep. J Anim Sci. 77: 1217-1223. doi: /1999.7751217x.

Huff, W., Harvey, B., Kubena, L., Rottinghaus, G. 1988. Toxic synergism between aflatoxin and T-2 toxin in broiler chickens. Poult Sci. 67 (10): 1418-1423. doi: 10.3382/ps.0671418. 
Hult, K., Teiling, A., Gatenbeck, S. 1976. Degradation of ochratoxin A by a ruminant. Appl Environ Microbiol. 32: 443-444.

Johansson, M., Emmoth, E., Salomonsson, A. \& Albihn, A. 2005. Potential risks when spreading anaerobic digestion residues on grass silage crops-survival of bacteria, moulds and viruses. Grass and Forage Science. 60: 175-185. doi: 10.1111/j.13652494.2005.00466.x.

Jouany, J. \& Diaz, D. 2005. Effects of mycotoxins in ruminants. The Mycotoxin Blue Book. Diaz D., Ed. Nottingham University Press. Nottingam, Inglaterra. Pp: 295-321.

Katzenellenbogen, B., Katzenellenbogen, J. \& Mordecai, D. 1979. Zearalenones: characterization of the estrogenic potencies and receptor interactions of a series of a fungar resorcyclic acid lactones. Endocrinology. 105: 33-40.

Keller, M., Keller, K., Monge, M., Pereyra, C., Alonso, V., Cavaglieri, L., Chiachiera, S. \& Rosa, C. 2012. Gliotoxin contamination in pre- and postfermented corn, sorgum and wet brewer's grains silage in Sao Paulo and Rio de Janeiro State, Brazil. J. Appl. Microbiol. 112 (5): 865-873. doi: 10.1111/j.1365-2672.2012.05273.x.

Keller, T., Nonn, H. \& Jeroch, H. 1998. The Effect of Sealing and of additives on the fermentation characteristics and mould and yeast counts in stretch film wrapped big-bale lucerne silage. Arch. Anim. Nutr. 51: 63-75.

Kiessling, K., Patterson, H., Sandholm, K. \& Olsen, M. 1984. Metabolism of aflatoxin, ochratoxin, zearalenonaralenone, and three trichothecenes by intact rumen fluid, rumen protozoa, and bacteria. Appl Envirn Microbiol. 47: 1070-1073.

Korosteleva, S., Smith, T. \& Boermans, H. 2007. Effects of feedborne Fusarium mycotoxins on the performance, metabolism, and inmunity of dairy cows. J. Dairy Sci. 90 (8): 3867-3873.

Kuilman, M., Maas, M., Judah, J. \& Fink-Gremels, J. 1986. Bovine hepatic metabolism of aflatoxin B1. J Agric Food Che. 46: 2707-2713. doi: 10.1021/jf980062x.

Kung, L. 2001. Silage fermentation and additives. In: Lyons T., Jacques K. (ed) Proceedings of Alltech's Seventeenth Annual Symposium. p.145-159.

Madhyastha, M., Marquardt, R. \& Abramson, D. 1994. Structure-activity relationships and interactions among trichothecene mycotoxins as assessed by yeast bioassay. Toxicon. 32 (9):1147-1152. doi: 10.1016/0041-0101(94)90398-0.

Manafi, M., Umakantha, B., Mohan, K. \& Narayana, H. 2012. Synergistic effects of two commonly contaminating mycotoxins (aflatoxin and T-2 toxin) on biochemical parameters and inmune status of broiler chickens. World App Sci J. 17 (3): 364-367.

Mansfield, M., Archibald, D., \& Jones, A. 2007. Relationship of Sphinganine Analog Mycotoxin Contamination in Maize Silage to Seasonal Weather Conditions and to Agronomic and Ensiling Practices. Phytopatology. 97 (4): 504-511. doi: 10.1094/PHYTO-97-4-0504. 
Mansfield, M. \& Kuldau, G. 2007. Microbiological and molecular determination of mycobiota in fresh and ensiled maize silage. Mycologia. 99 (2): 269-278.

Miller, D. 2008. Mycotoxins in small grains and maize: old problems, new challenges. Food Add. Cont. 25 (2): 219-30. doi: 10.1080/02652030701744520.

Mostrom, M. 2012. Zearalenone. P 1267-1268. In: R. Gupta (ed). Veterinary Toxicology. Ed. $2^{\mathrm{a}}$ edición. Elsiever. Oxford, Estados Unidos.

Mostrom, M. \& Raisbeck, M. 2012. Tricothecenes. p 1242-1257. In: R. Gupta (ed). Veterinary Toxicology. Ed.. $2^{a}$ edición. Elsiever. Oxford, Estados Unidos.

Müller, H. \& Amend, R. 1997. Formation and disappearance of mycophenolic acid, patulin, penicillic acid and PR toxin in maize silage inoculated with Penicillium roqueforti. Arch. Anim. Nutr. 50 (1): 213-225. doi: 10.1080/17450399709386133.

Nešic, S., Grubic, G., Adamovic, M., Đorðevic, N., Stojanovic, B. \& Bo, A. 2010. Uso de la zeolita como absorbente de la zearalenona en la nutrición de terneros. Rev. Cub. Cienc. Agrícol. 44 (3): 227-233.

Nielson, A. 2012. Aflatoxin testing not a foolproof solution. South east farm press.7 noviembre.

Notermans, S., Kozaki, S. \& Van Schothorst, M. 1979. Toxin production by Clostridium botulinum in grass. Appl Environ Microbiol. 38 (5): 767-771.

O' Brien, M., Kiely, P., Forristal, P. \& Fuller, H. 2008. Fungal contamination of big-bale grass silage on irish farms : predominant mould and yeast species and features of bales and silage. Grass and Forage Science. 63: 121-137.

Osuna, O., Edds, G. \& Blankespoor, H. 1977. Toxic effects of aflatoxin B1 in male Holstein calves with prior infection by flukes (Fasciola hepatica). Am J Vet Res. 38: 341-349.

Ovando, M., Ozsisli, B., Anderson, J., Whitney, K., Ohm, J. \& Simsek, S. 2013. Analysis of deoxynivalenol and deoxynivalenol-3-glucoside in hard red spring wheat inoculated with Fusarium graminearum. Toxins. 5 (12): 2522-2532. doi: 10.3390/toxins5122522.

Osweiler, G., Kehrli, M., Stabel, J., Thurston, J., Ross, F. \& Wilson, T. 1993. Effects of fumonisincontaminated corn screenings on growth and health of feeder calves. J Anim Sci. 71 (1): 459-466.

Peña, G., Pereyra, C., Armando, M., Chiacchiera, S., Magnoli, C., Orlando, J., Dalcero, A., Rosa, C. \& Cavaglieri, L. 2010. Aspergillus fumigatus toxicity and gliotoxin levels in feedstuff for domestic animals and pets in Argentina. Letters in Applied Microbiology. 50 (1): 77-81. doi: 10.1111/j.1472-765X.2009.02756.x.

Poapolathep, A., Kumagai, S., Suzuki, H. \& Doi, K. 2004 (a). Development of early apoptosis and changes in T-cell subsets in mouse thymocyte primary cultures treated with nivalenol. Exp Mol Pathol. 77 (2): 149-152. doi: 10.1016/j.yexmp.2004.04.004. 
Poapolathep, A., Nagata, T., Suzuki, H., Kumagai, S. \& Doi, K. 2003. Development of early apoptosis and changes in lymphocyte subsets in lymphoid organs in mice orally inoculated with nivalenol. Exp. Mol. Pathol. 75 (1): 74-79. doi: 10.1016/S0014-4800(03)00027-3.

Poapolathep, A., Sugita-konishi, Y., Phitsanu, T., Doi, K. \& Kumagai, S.. 2004 (b). Placental and milk transmission of trichothecene mycotoxins, nivalenol and fusarenon $X$, in mice. Toxicon. 44 (1): 111-113. doi: 10.1016/j.toxicon.2004.04.005.

Puel, O., Tadrist, S., Galtier, P., Oswald, I. \& Delaforge, M. 2005. Byssochlamys nivea as a source of mycophenolic acid. App. Environ. Microbiol. 71 (1): 550-553. doi: 10.1128/ AEM.71.1.550-553.2005.

Rashedi, M., Hamid, R., Mohammad, A., Hamed, A. \& Ebrahim, R. 2012. Zearalenone contamination in barley, corn, silage and wheat bran. Toxicol. Ind. Health. 28 (9): 77982. doi: 10.4236/as.2013.412084.

Rasmussen, P., Nielsen, K., Ghorbani, F., Spliid, N., Nielsen, G. \& Jørgensen L. 2012. Ocurrence of differente tricothecenes and deoxynivalenol-3--D-glucoside in naturally and artificially contaminated Danish cereal grains and whole maize plants. Mycotoxin Res. 28 (3): 181-190. doi: 10.1007/s12550-012-0133-z.

Reyes, W., Isaías, S., Rojo, F., Jimenez, C., De Lucas, E., Hernández, J. \& Ramírez, A. 2008. Occurrence of fungi and mycotoxins in corn silage, Jalisco State, Mexico. Rev. Iberoam. Micol. 25 (3): 182-185.

Roigé, M., Aranguren, S., Riccio, M., Pereyra, S., Soraci, A. \& Tapia, M. 2009. Mycobiota and mycotoxins in fermented feed, wheat grains and corn grains in Southeastern Buenos Aires Province, Argentina. Rev. Iberoam. Micol. 26 (4): 233-237. doi: 10.1016/j. riam.2009.03.003.

Roine, K., Korpinen, E. \& Kallela, K. 1971. Mycotoxicosis as a probable cause of infertility in dairy cows. Nord Vet Med. 23: 628-633.

Seeling K., Dänicke, S., Ueberschär, K., Lebzien, P. \& Flachowsky, G. 2005. On the effects of Fusarium toxin-contaminated wheat and the feed intake level on the metabolism and carry over of zearalenone in dairy cows. Food Add Cont. 22 (9): 847-855.

Shimshoni, J., Cuneah, O., Sulyok, M., Krska, M., Galon, R., Sharir, N. \& Shlosberg, A. Mycotoxins in corn and wheat silage in Israel. Food Add Cont. 30 (9): 1614-1625. doi: 10.1080/19440049.2013.802840.

Skladanka, J., Adam, V., Dolezal, P., Nedelnik, J., Kizek, R., Linduskova, H., Alba, J. \& Nawrath, A. 2013. How Do Grass Species, Season and Ensiling Influence Mycotoxin Content in Forage? Int. J. Environ. Res. Public Health. 10 (11): 6084-6095. doi: 10.3390/ijerph10116084.

Skladanka, J., Nedelnik, J., Adam, V., Dolezal, P., Moravcova, H. \& Dohnal, V. 2011. Forage as a Primary Source of Mycotoxins in Animal Diets. Int. J. Environ. Res. Public Health. 8 (1): 37-50. doi: 10.3390/ijerph8010037. 
Smith, G. 2012. Fumonisins. P 1206. In: R. Gupta (ed). Veterinary Toxicology. Ed.. $2^{\text {a }}$ edición. Elsiever. Oxford, Estados Unidos.

Storm, I., Kristensen, K., Raun, B., Smedsgaard, J. \& Thrane, U. 2010. Dynamics in the microbiology of maize silage during whole-season storage. J. Appl. Microbiol. 109 (3): 1017-1026. doi: 10.1111/j.1365-2672.2010.04729.x.

Streit, E., Schwab, C., Sulyok, M., Naehrer, K., Krska, R. \& Schatzmayr, G. 2013. Multi-Mycotoxin Screening Reveals the Occurrence of 139 Different Secondary Metabolites in Feed and Feed Ingredients. Toxins. 5: 504-523. doi: 10.3390/toxins5030504.

Suzuki, S., Satoh, T. \& Yamazaki, M. 1977. The pharmacokinetics of ochratoxin A in rats. Jpn J Pharmacol. 27: 735-744. doi: 10.1254/jjp.27.735.

Tobía, C., Rojas, A., Villalobos, E., Soto, H. \& Uribe, L. 2004. Sustitución parcial del alimento balanceado por ensilaje de soya y su efecto en la producción y calidad de la leche de vaca, en el trópico húmedo de Costa Rica. Agronomía Costarricense. 28 (2): 27-35.

Uegaki, R., Kobayashi, H., Inoue, H., Tohno, M. \& Tsukiboshi, T. 2013 (a). Changes in fumonisin production in rice grain during ensiling. Anim. Sci. J. 84 (1): 48-53. doi: 10.1111/j.17400929.2012.01028.x.

Uegaki, R., Tsukiboshi, T. \& Tohno, M. 2013 (b). Changes in the concentration of fumonisin, deoxynivalenol and Zearalenone in corn silage during ensilage. Anim. Sci. J. 84 (9): 656-662. doi: 10.1111/asj.12053.

Upadhaya, S., Park, M. \& Jong, K. 2010. Mycotoxins and their biotransformation in the rumen. Asian-Aust J Anim Sci. 23 (9): 1250-1260. doi: 10.5713/ajas.2010.r.06.

Van Asselt, E., Azambuja, W., Kastelein, P., De Rijk, T., Stratakou, I. \& Van Der Fels-Klerx, H. 2012. A Dutch field survey on fungal infection and mycotoxin concentrations in maize. Food Add. Cont. 29 (10): 1556-1565. doi: 10.1080/19440049.2012.689997.

Vandenbroucke, V., Croubels, S., Verbrugghe, E., Boyen, F., De Backer, P., Ducatelle, R., Rychlik, I., Haesebrouck, F. \& Pasmans, F. The mycotoxin deoxynivalenol promotes uptake of Salmonella Typhimurium in porcine macrophages, associated with ERK $1 / 2$ induced cytoskeleton reorganization. Vet Res. 40 (6):64. doi: 10.1051/vetres/2009045.

Ványi, A., Szemerédi, G. \& Szailer, E. 1974. Fusariotoxicosis in a cattle farm. Magy Állatorv Lapja. 29: 544-546.

Weaver, G., Kurtz, H., Behrens, J., Robison, T., Seguin, B., Bates, F. \& Mirocha, C. 1986. Effect of zearalenone on dairy cows. Am. J. Vet. Res. 47 (8): 1826-1828.

Wilkinson, J. 1999. Silage and animal health. Nat. Toxins. 7 (6): 221-232. doi: 10.1002/1522-7189(199911/12)7:6<221::AID-NT76>3.0.CO;2-H.

Wu, F., Bhatnagar, D., Bui-klimke, T., Carbone, I., Hellmich, R., Munkvold, G., Paul, P., Payne, G. \& Tackle E. 2011. Climate change impacts on mycotoxins risk in US maize. World Mycot J. 4 (1): 79-93. doi: 10.3920/WMJ2010.1246. 